\title{
Strategizing Public Sector Hospitals In Megacity Karachi: A Case Study On Gender Based Healthcare Facility Selection Criteria And Concerns (From Demand And Supply Perspective)
}

\author{
Shamaila Burney \\ \& \\ Khalid Mahmood Iraqi \\ Department of Public Administration \\ University of Karachi
}

\begin{abstract}
Karachi is the most populous city in Pakistan and it plays an important role in urban demography of Pakistan. It is growing rapidly, as every fifth urban citizen lives here. This urbanization creates serious challenges for all sectors of Karachi. Especially the health sector, from demand and supply view point is facing serious challenges in terms of non-availability of qualified doctors, specifically female doctors, medicines, latest equipment, poor infrastructure, and patient's queues belonging to other rural areas because of the lack of quality healthcare facilities, makes the public hospitals crowded and overburdened. Like all over Pakistan, public sector hospitals are very much neglected in Karachi also and needs special consideration. The focus should be on developing patient oriented supply chains for efficient patient's care and healthcare facilities. Moreover, the case study of Qatar hospital a part of our basic research study also highlighted the depriving condition for women patients' in Emergency Department, because only male doctors are there but female doctors are not available. Although we observed that the gender wise daily patient flow was consist of $65 \%$ females, whereas only $35 \%$ male patients. The study suggests that there is an urgent need of women doctors and paramedics staff in the public sector hospitals of suburbs of Karachi. This paper presents a synoptic view of concerns of the residents of Karachi, and identification of their selection criteria of health care facilities. The study also aimed to provide solutions and recommendations for the improvement of these facilities. Cross sectional questionnaire and random sampling with two stage clusters sampling was used to record the responses of 1991 households, $46 \%$ respondents were female and $54 \%$ were male. Among the total of 11127 respondents, only 580, (5.2\%) sought treatment in public health hospitals and, 2440 (21.9\%) visited private hospitals. Research results shows that Cost is the only significant factor because of which people opt for treatment at public healthcare facility.
\end{abstract}

Keywords: Megacities, Karachi, Pakistan's Health Sector, Health Care Facility Selection Criteria, Concerns of People, Demand Side, Supply Side, Gender. 
180 Strategizing Public Sector Hospitals in Megacity Karachi: A Case Study on Gender Based Healthcare Facility Selection Criteria and Concerns (From Demand and Supply Perspective)

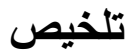

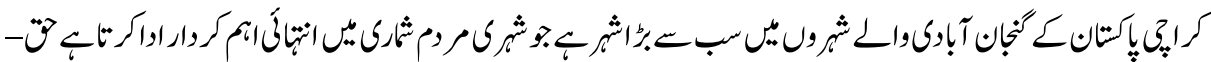

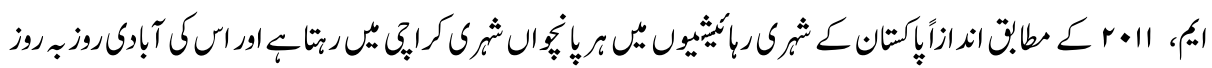

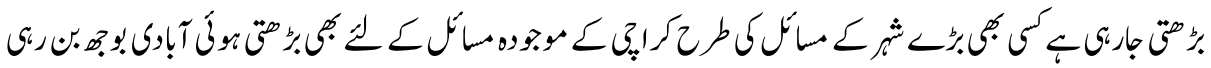

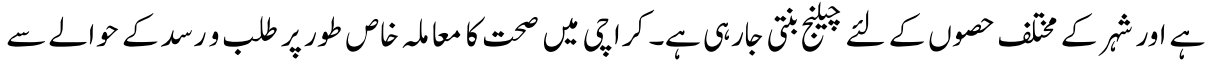

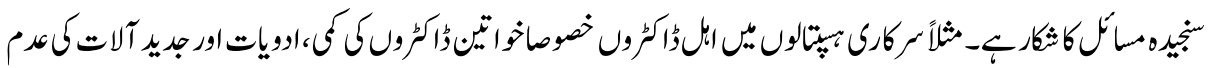

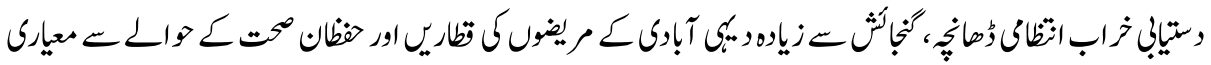

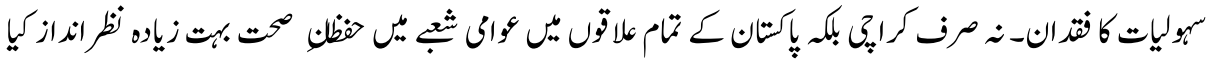

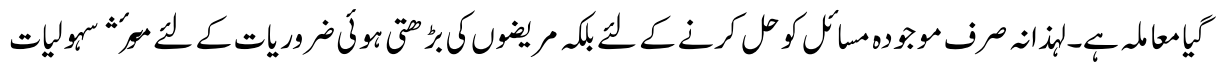

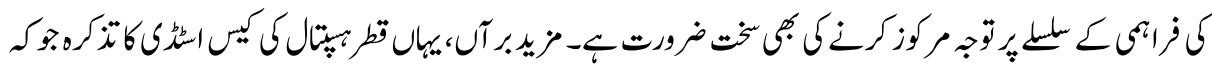

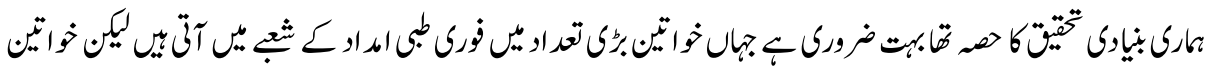

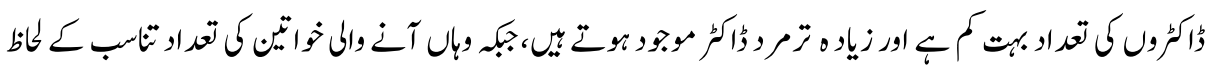

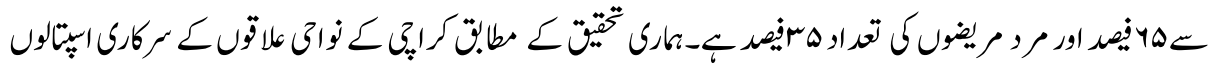

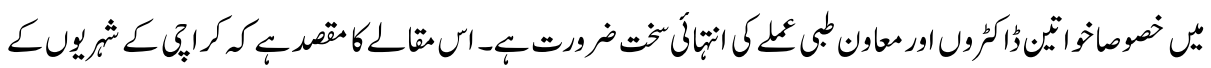

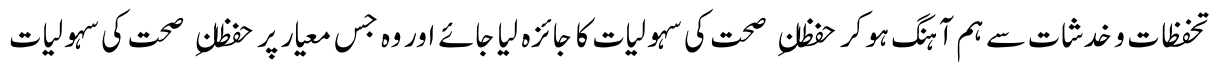

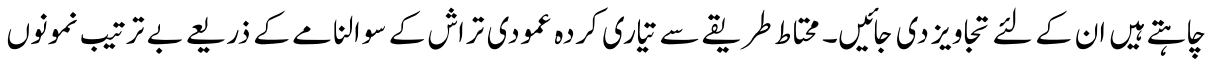

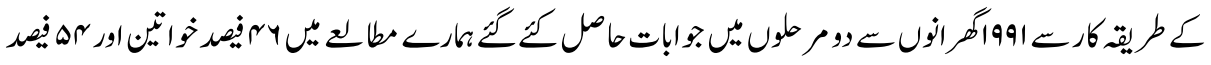

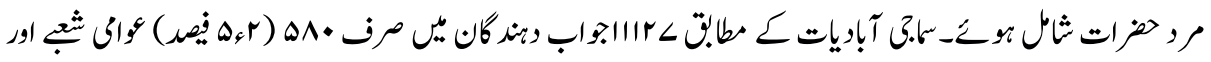

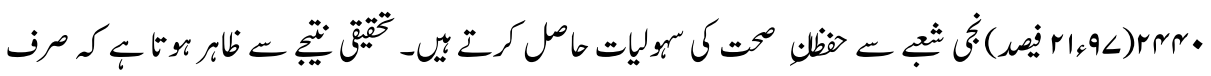

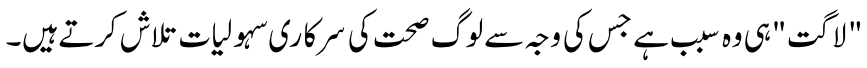

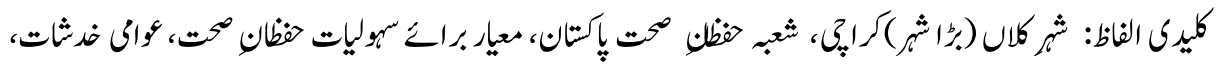

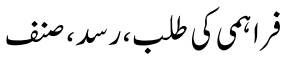

\section{Introduction}

The world's urban population is growing at an ever faster rate, giving rise to the growth of mega cities on the globe. A megacity, by definition is an urbanized area with a population of at least 10 million (UNCHS, 1996). According to UN Habitat, two-third of the world's population is likely to live in cities until 2030. As estimated by World Urbanization 
Prospect 2014, there will be an increase in number of megacity by 2030, (Fig 1), the megacities listed by the UN already have reached a total population of 280 million and are considered the growth engines of their relevant national economies. But with this rapid growth there is also a rapid growth in the challenges megacities are facing. The major key issue of this exceptional growth of population in megacities is on the city's infrastructure. Urban residents need and deserve essential and basic necessities of quality living such as clean drinking water, stable electricity, transportation system and most importantly a better healthcare system with cost-effective quality care and easy access to healthcare facilities.

Megacities are a new spatial urban form with important implications for public health (Pappas G. 2011). Healthcare structures in megacities are at crucial point due to significant demographic and epidemiological changes (New Cities Foundation 2013). The major reason behind this is the phenomenon of rapid urbanization i.e., the rapid rise in population mainly in the form of internal migration from rural to urban areas of the country. This new reality poses serious concerns and unprecedented pressure on health support systems in (Nasir, F., Herani, G.M \& Nazwaz, A. 2012) developing countries, especially in megacities like Karachi which are already overburdened and constrained by limited resources. Particularly healthcare services in the public sector are an ignored and mistreated area and hence needs to be taken under special consideration. The major reasons for this are financial limitations and restrictions, and the socio-cultural feature of high, low income demand for public sector hospital services (Chisolm et al., 2010).

Pakistan's public healthcare sector is riddled with numerous problems, constraints, challenges and contradictions that obstructs the smooth functioning of the health care system \& service delivery, especially, in Karachi (Zaidi, S.Akbar, 1986). Megacity Karachi- the capital city of the province of Sindh and the only mega city of Pakistan with an estimated population of over 22 million, ranked as $7^{\text {th }}$ largest mega city in the world as compared to other mega urban cities is greatly neglected in Health sector (Shaikh B.T., 2011). Healthcare in Karachi is deeply entrenched in corruption, shortage of qualified doctors and paramedics in public hospitals, unavailability of medicines and poor quality of infrastructure and health facilities accessibility. As our research show, the people of Karachi have, in general, little or no access to healthcare facilities in public hospitals.

\section{Comparison of public (Pub)h and private (Pvt.)h on accessibility of healthcare facility( N- 11127)}

\begin{tabular}{|c|c|c|c|}
\hline Variable & Score & Df & Sig. \\
\hline Easy Access (Pub)h & 4.507 & 1 & .034 \\
\hline Easy access (Pvt)h & 12.36 & 1 & .000 \\
\hline
\end{tabular}

Source: Burney ,S , Iraqi ,Khalid ,2015 results generated under the project of 'Managing Mega-Cities A case study of -Karachi' survey in George Mason University-USA University of Karachi Partnership program. 
Consequently, the burden of health facilities has shifted to the private sector, thus adding financial stresses to people across the city. This paper examines the concerns of the people related to health and how these concerns are influencing the behaviour of people with the help of Quality Index development using the data of Karachi megacity survey conducted in 2015 and it also examines people criteria of selection of healthcare facilities. As Patient's choice of health-care services depends on two important factors, primarily on patients' characteristics and on the features available at the health-care facilities (Karkee, R. \& Kadariya, K. 2013). The results reported inform policy recommendations and strategies for managing the problems of health sector in Karachi.

Following this introduction to the research theme, Section 2 puts forward a discussion on the health care structure of Pakistan and health issues with special reference to megacity Karachi and identifying areas that need special considerations of healthcare facility administrators Section 3 discusses in particular a case of Karachi 's healthcare facilities Section 4 describes the research design in detail comprising of four different sections related to research instrument designing and methodology, Section 5 presents the results of the survey research analysis and reports responses of the sample residents of Karachi along with interpretive analysis section 6 concludes the study and Section 7 proposes policy recommendations for bringing improvements in Healthcare infrastructure of Karachi with emphasis on improvement in healthcare service efficiency, as grounded through the expectations of the patients.

\section{Literarture Review}

Pakistan's health care system consists of a three-tiered health delivery system, including primary, secondary and tertiary care. This healthcare facilities structure consists of Basic Health Units (BHU), Community Health Care Services through Lady Health Workers, Rural Health Centres, Tehsil hospitals, Dispensaries, District hospitals and well equipped Tertiary level teaching hospitals. Despite Karachi's extensive health care infrastructure, it is un able to deliver optimal health services and care as a consequence number of issues and challenges that the health sector of Pakistan specifically Karachi is facing, including lack of motivation among members of the healthcare workforce due to lack of career prospects, deep-rooted corruption, uneven distribution of resources, lack of medicines and the latest diagnostic and treatment equipment, and overall unsatisfactory health infrastructure (World Health Organization, 2004). Moreover, Pakistan spends an exceptionally low percentage of its Gross Domestic Product (GDP) on health, only $0.5 \%$. This is leading to further inefficiency with the government's ability to cope up with the growing needs for required medicine and laboratory support resulting in an out-of-pocket expenditure on health of around $80 \%$. According to World Bank (2010) Pakistan is still striving to achieve most health-related Millennium Development Goals MDGs. Though there has been an improvement in the MDGs of education sector, the Health sector still 
remains on the margins of the development landscape (World Bank, 2010). Thus Pakistan is facing a number of major challenges in improving health outcomes. Keeping in view the current level of government expenditure on health, achieving an improvement in this sector seems doubtful. To improve health sector in Karachi, requires strengthening four important domains of the health care system. i.e. health care delivery, public health, personal health management, and health-related research (Detmer, D.E. 2003).

The quality of healthcare services in public hospitals is showing a downward trend and the rapid growth in population due to immigration and births is imposing increasing pressure on public hospitals. This is shifting the burden onto the private sector to meet the needs and to bridge the gap between increasing demands and public provision of health. The role of the private sector in providing up to standard facilities is increasing and because of poor public sector performance, public sector health facilities role is diminishing as survey conducted by (Jannati, A., Bahrami, MA., Gholizadeh, M., Alizadeh, L. \& Khodayari, MT. 2013) also highlighted that today's patients are more sensitive in selection of their healthcare facility than before and are more concerned about their health than previously. Moreover, the total expenditure of health care in Pakistan is Rs 185 billion, of which the private sector spends Rs 121 million while public sector only shares Rs 59.5 million (Ahmed, S., Khan, A.A. \& Khan, A. 2011). To provide quality patient care and performance improvement, Hospitals have now realised the importance of application of performance management tools like ISO 9000 certifications, TQM, Benchmarking, Balanced Scorecard (BSC) and other tools to enhance the performance of health service capacity, quality and service delivery in hospitals. According to (Rabbani F. 2011) a research conducted at an ISO certified hospital in Karachi also showed positive performance indicators after successful implementation of BSC.

Pakistan and particularly Karachi is facing serious health issues while going through epidemiological transition and demographic changes. In this context the public health service delivery presents an uneven distribution of resources with unsatisfactory performance. After the $18^{\text {th }}$ amendment to the constitution responsibility for the health sector has been devolved to the provinces yet responsibility for distribution and revenue generation sources still remain unclear between the different tiers. For achieving significant improvements in the health sector, it is important to frame the development and maintenance of health structure in a way that keeps consideration focused not only on short term health outcomes but is also able to address and improve the long-term health status of the population

Karachi, a megacity with an estimated population of more than 23.7 million (PPI, 2015) has three established and running tertiary-care public hospitals, i.e., Jinnah Postgraduate Medical Centre (JPMC), Civil Hospital Karachi (CHK) and Abbasi Shaheed Hospital (ASH). Nearly 75 percent of households in Karachi fall in the lower-middle and low income brackets with an average monthly income PKR 15,000 (Pakistani Rupee) (Khan 
Amina, 2014) varying significantly across the upper and lower income categories. Keeping in view the large income gap of the city's population, access to a private healthcare facility puts considerable financial strain. Still, the private sector dominates the health sector of Karachi despite their high cost of treatment and facilities as the state run healthcare facilities have failed. There is a dire need to work on the improvement of Public healthcare facilities in Karachi to make it efficient enough to address the needs of lower income patient' needs $\&$ health care. The basic objective of this research study is to identify the factors that people in Karachi consider while selecting a healthcare facility and to examine the concerns of people, while selecting healthcare facility in Karachi.

\section{Research Methodology}

Both Qualitative and quantitative research tools are used in this research to gain understanding of healthcare facility selection criteria residents of Karachi uses to select healthcare facility. Furthermore this study also explores gender based demand and supply facilities in public sector hospitals of Karachi. This study is based on a cross-sectional survey that was carried out from December 2015 till January 2016 from total sample of 13,233 households, Megacity Karachi was categorized into 18 administrative towns and 6 cantonment areas. $1 \%$ sample blocks are taken from each strata through systematic random sample. In all blocks every 15 samples of household were selected through Simple Random Sampling with random starting point for interview. Total 1980 household were visited for interview. 11127 individuals were interviewed, selected through systematic random sampling from 132 blocks.

A well structured survey questionnaire was designed by researcher and the survey was carried out by Karachi office of the Pakistan Bureau of Statistics under the project of 'Managing Mega-Cities A case study of -Karachi' in George Mason University -under state deparment's University Partnership program. A two stage stratified sampling technique was employed to draw sample.

Case Study of Qatar Hospital is also included in our research work to study the real time data in terms of gender wise distribution of supply side facilities (i.e. Doctors and paramedics staff available in hospitals) for patients arriving in hospital for treatment.

\section{Research Instrument Development}

The major data is derived from a cross-sectional household survey's section on the utilization of healthcare facilities A questionnaire is used to obtain information on household members in the following areas(i)Socio demographic characteristics; (ii) Health problems in the year prior to the interview; (iii) Type of healthcare facility chosen in the first instance; and (iv) Reasons for the choice of a healthcare facility (v) Factors giving rise to health issues in Karachi(vi) Administrative issues that are weakening the public health infrastructure of Karachi. 
The questionnaire was translated into Urdu and was pretested on 25 households. The results of this pilot questionnaire were used to make the questionnaire more locally contextualized. This research focuses on the studying the healthcare facility selection criteria using following hypothesis:

H1: Availability of specialized doctors impacts the selection of a healthcare facility.

H2: Cost of care impacts the selection of healthcare facility.

H3: Cleanliness and hygiene are significant factors on the selection of a healthcare facility.

H4: Quality of treatment a patient receives at a hospital has an impact on the selection of a healthcare facility.

H5: Proximity has an impact on selection of healthcare a facility.

H6: Behaviour of medical practitioners has an impact on the selection of a healthcare facility.

H7: There is an impact of availability of medicines on the selection of a healthcare facility.

\section{Research Model}

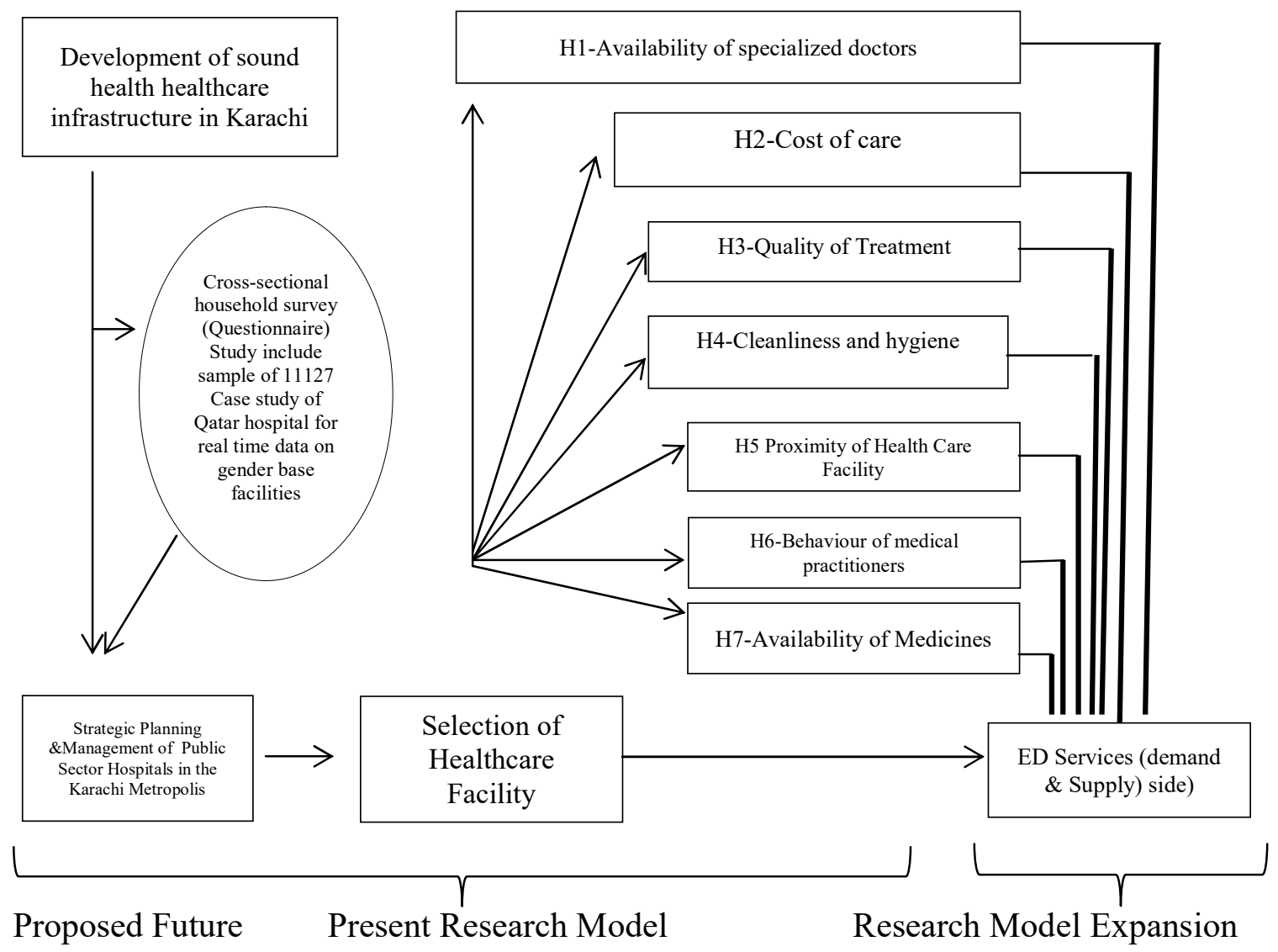

Figure 1: Shows present and proposed future Research Model adopted in this study 
The current study investigated the concerns of people when selecting health care facility in Karachi along with the identification of selection criteria that the residents of Karachi use to select Healthcare facility. This study aims at providing solutions and recommendations for the improvement of Health care facilities in Karachi with special reference of gender based demand and supply facilities in hospitals. Thus the study is limited to megacity Karachi only; in future similar methodology can be adopted to expand the ambit of research to other cities as well. Moreover, the proposed model in the study can be extended to include Emergency department services and patient satisfaction level as shown in proposed study model above and we have focused on this in our future research study. Methodologically, the future studies can consider the role of supply chains and more specifically patient oriented supply chains in making health service sector more efficient.

\section{Definitions and Classification of Variables}

Public Health care facilities are those state owned facilities that are run and financed by government. Whereas other non- state healthcare facilities are categorized as Private healthcare facilities.

The concerns of people while choosing healthcare facilities were assessed with the help of Index development, in which five variables were used i.e. Age, Level of Education, district of residence, Income and Language (Urdu). The result of concern shows that the more educated a person is the more concerned he/she is about quality of a healthcare facility.

The reason for choosing healthcare facilities both for public and private health care facilities is assessed by use of seven different variables that residents of Karachi keeps in mind while selecting healthcare facilities, these variables are (1) Cost of care (2) Quality of treatment (3) specialised doctors (4) cleanliness/hygiene (5) Availability of medicine (6) Quality of health personnel behaviour and (7) Easy access. However, it is strongly felt that emergencies services management is also of immense importance in many cities like Karachi both from supply and demand viewpoint and needs urgent attention. The research model above conceptualizes comprehensive approach to all such aspects. Patient satisfaction is an important factor for measuring quality of care and services delivery in megacity -Karachi in the Emergency departments of Tertiary care hospitals of Karachi. Patient surveys are carried out to measure the efficiency of ED worldwide.

The education status was classified into three different categories (1) Middle (up to 5 years of education in school) (2) Secondary \& High (from 6 years to 12 years of education (3) B.A. \& Above (14 years and above).Variable Urdu is classified as Urdu and No Urdu speaker. 
During case study observation at Qatar hospital, our focus was on both demand side variables (i.e. Gender wise patient flow) and supply side variables (i.e. Doctors, nurses, paramedical staff and equipment) based on observation and expert opinion.

\section{Research Limitations}

This study is partially supported by quantitative analysis. As such it provides insight into the views of representative patients who avail healthcare facilities, basic health issues of Karachi but lacks information from policy makers' points of view.

The sample covers only one city; hence there is a limitation of generalizability to the entire health management plan of the country and to healthcare issues faced by megacities in general. Also, since it is one-time survey, it will not be able to predict the trends of the health sector. However, it will definitely provide a basic framework or model that can be further implemented in other cities. For example, working hypotheses can be developed based on the Karachi research which can be the focus of future research that can be conducted with a methodology that enables generalizations to other megacities in developing countries.

\section{Case Study Analysis}

Karachi's public Sector Hospital is taken as a case study to collect and understand the real time data on the gender wise patient flow in a public sector hospital and the reason of visiting the selected healthcare facility. During study, patient's flow was observed in a hospital. Following chart represents the patient's flow on the basis of observation and expert's opinion taken during in-depth interview. The findings shows that $65 \%$ female patients visits hospital daily, which shows that there is an urgent need to enhance the gender wise ratio of Doctors and paramedics staff in the hospital, as there is a lack of Female doctors in hospital.

\begin{tabular}{|l|l|}
\hline \multicolumn{2}{|c|}{ Gender Base Patient Flow ED of Public Sector Hospital } \\
\hline Female Patients arrived & $65 \%$ \\
\hline Male Patient arrived & $35 \%$ \\
\hline
\end{tabular}

\section{Figure 2: Represents gender base patient flow in ED of public sector hospital}

The selected public sector hospital provides free of cost treatment to patients and is the only hospital providing medical care to all local residents of Orangi town and nearby population. The doctor and patient ratio was observed approximately 1:10 patients, which shows that there is an urgent need to increase the number of both male and female doctors and staff in hospitals to deal with female patients. Pakistani society is patriarchal in nature, where generally females suffer discrimination in every walk of life (Ali, S. Mubashir, 2000). Likewise is observed in selected, public sector hospital as only male 
doctors and staff was available in hospital's ED. Moreover, there is also an immense need to enhance the infrastructure, equipment and latest medical care facilities in hospital.

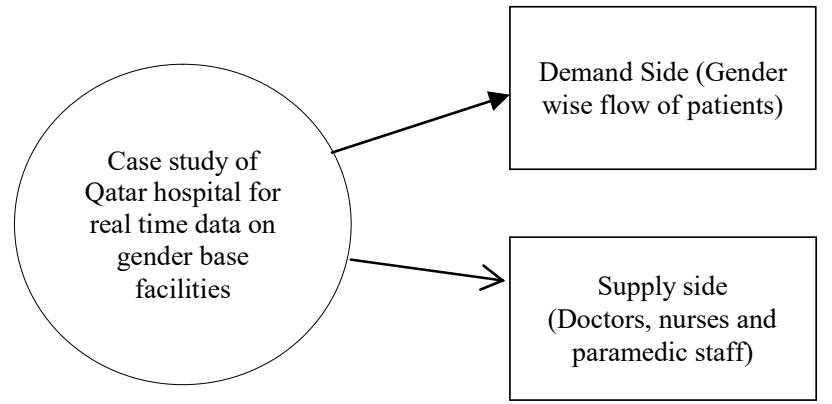

Figure3: presents Case study Research Model under study

\section{Study Area and Socio-Demographic Characteristics of Respondents}

Megacity Karachi, known as" city of lights" is the capital of the Sindh province and is the main seaport, financial and economical centre of Pakistan. According to Demographia World Urban Areas report, Karachi's population has shown an estimate of $80.5 \%$ increase in the last decade and is ranked as the $7^{\text {th }}$ largest mega city of the world. Karachi has total population of 22 million (estimated). For this study we categorized Karachi into its 18 administrative towns and 06 cantonments. Data analysis is done using SPPS version 24.

Table: 1

Socio Demographic Characteristics Of The Respondents $(\mathrm{N}=11127)$

\begin{tabular}{|c|c|}
\hline Variables & $\mathbf{N}(\%)$ \\
\hline Gender & \\
\hline Male & $54 \%$ \\
\hline Female & $46 \%$ \\
\hline Education & $17.4 \%$ \\
\hline No School & $37 \%$ \\
\hline Middle & 30.4 \\
\hline Secondary \& High & 15.2 \\
\hline B.A. \& Above & $75.1 \%$ \\
\hline Age Group & $19.3 \%$ \\
\hline Below 40 & $5.6 \%$ \\
\hline $40-59$ & 67.4 \\
\hline $60-$ above & 32.6 \\
\hline Ethnicity & \\
\hline Urdu & \\
\hline No Urdu & \\
\hline
\end{tabular}


Table 1 presents the Socio- demographic characteristics of the respondents. Among the total of 11127 respondents, Gender is one of the organizing principles of Pakistani society $(\mathrm{ADB}, 2000) .54 \%$ of respondents were male and $46 \%$ of respondents were Female. Most of the respondent were aged below 40 (75\%) only 30\% of the respondents were literate and $37 \%$ of the respondents were only Middle pass. This data includeall respondents who had visited Public or Private Healthcare Facility, in last 12 months prior to the survey was conducted to seek medical treatment either for themselves or for the family members. Choice of healthcare facility was recoded in analysis as 1 Public healthcare facility and 0 for private healthcare facility as 0 in order to identify the number of people.

Following graph shows the percentages of visits people did to different type of health care facility during the past 12 months, Out of the sample of 11127 , only 3150 responded and 7977 were missing. Only $1.9 \%$ visited government clinics and $1.1 \%$ visited clinics operated by charitable organizations. Most of the respondent i.e. $65 \%$ visited private clinics and only $16.5 \%$ visited Government hospitals while $2.2 \%$ visited hospitals operated by charitable organizations. While $12.2 \%$ respondent visited private hospitals.
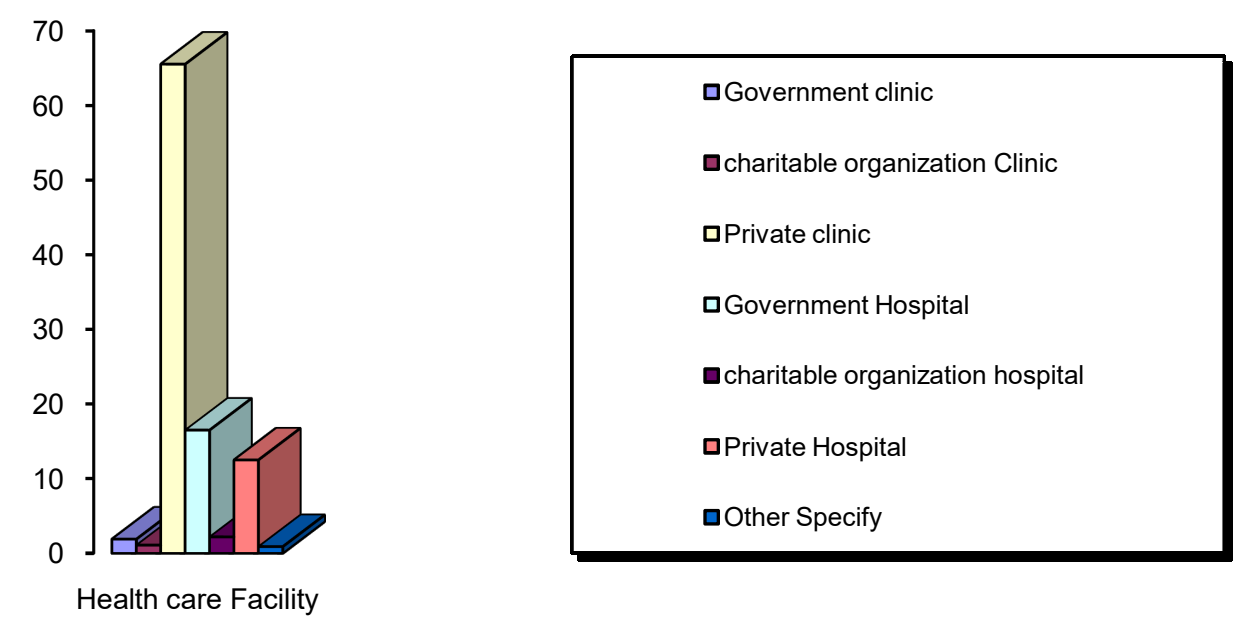

\section{Survey Results}

The paper presents following important findings and data from this study. Table 2 presents the results of logistic regression model A, for reasons of selection of Public Healthcare facility (Pubh), Variables used to measure choice of public healthcare facilities were Cost, quality, hygiene, availability of medicines \& access criteria. 
190 Strategizing Public Sector Hospitals in Megacity Karachi: A Case Study on Gender Based

Healthcare Facility Selection Criteria and Concerns (From Demand and Supply Perspective)

Among the total number of respondent 580, (5.2\%) of total 11127 respondents) who used public healthcare facilities said that the only significant factors/reasons of choosing public Health is Cost of care (.000) and cleanliness/hygiene (.034).

Table: 2

\begin{tabular}{|l|c|c|c|}
\hline \multicolumn{1}{|c|}{ Variables } & \multicolumn{3}{c|}{$\begin{array}{c}\text { Model A } \\
\text { Public health care Facility (Pubh) }\end{array}$} \\
\hline & Df & Sig. & Exp(B) \\
\hline Cost of care & 1 & .000 & 1.954 \\
\hline Quality of treatment & 1 & .820 & 1.093 \\
\hline Specialized doctor & 1 & .266 & .834 \\
\hline Cleanliness / hygiene & 1 & .034 & 8.489 \\
\hline Availability of medicine & 1 & .078 & 1.922 \\
\hline $\begin{array}{l}\text { Quality of health } \\
\text { personnel behaviour }\end{array}$ & 1 & .469 & .872 \\
\hline Easy access & 1 & & 2.556 \\
\hline Constant & 1 & .111 & .001 \\
\hline . a. variable(s) entered on step 1: cost, quality, hygiene, meds, paramed, haccess \\
\hline
\end{tabular}

Whereas Quality is the least preferable factor (.820) for those who visited public healthcare facility. Our research result shows that it is highly predictable that respondents do not prefer public healthcare facility at first instance.

\begin{tabular}{|l|l|l|l|}
\hline \multicolumn{3}{|c|}{ Model Summary -Pubh } \\
\hline Step & $\mathbf{- 2}$ log likelihood & Cox \& Snell R Square & Negelkerke R Square \\
\hline 1 & 4418.542 & .006 & .017 \\
\hline $\begin{array}{l}\text { a. Estimation terminated at iteration number } 8 \text { because parameter estimates changed } \\
\text { by less than .001 }\end{array}$ \\
\hline
\end{tabular}

Logistic regression model summary of Pubh model shows that there is a $6 \%(.006)$ to $17 \%$ (.017) variation is observed, hence the week results shows that very few people support the idea of visiting public healthcare facilities at first instance. 
Table: 3

\begin{tabular}{|l|c|c|c|}
\hline \multicolumn{1}{|c|}{ Variables } & \multicolumn{3}{c|}{ Model B } \\
& Private health care Facility (Pvth) \\
\hline Cost of care & Df & Sig. & Exp(B) \\
\hline Quality of treatment & 1 & .000 & .130 \\
\hline Specialized doctor & 1 & .011 & 1.612 \\
\hline Cleanliness / hygiene & 1 & .000 & 1.972 \\
\hline Availability of medicine & 1 & .007 & 2.550 \\
\hline Quality of health personnel behaviour & 1 & .054 & 1.500 \\
\hline Easy access & 1 & .003 & .673 \\
\hline Constant & 1 & .044 & 1.722 \\
\hline a. variable(s) entered on step 1: cost, quality, hygiene, meds, paramed, haccess \\
\hline
\end{tabular}

Table 3 infers the results of logistic regression of Model B- Pvth, for those who visited Private Health care Facilities, Same variables were used as in Model A -Pubh for private health care facilities responses also. From the total of 11127 respondents, $2440(21.9 \%)$ Respondents visited private healthcare facilities. The results shows Cost of care (.000), quality of treatment (.011) specialized doctors (.000), cleanliness/hygiene (.007), Quality of Health Personnel (.003) and easy access(1) (.044) as significant factors/reasons for choosing private healthcare facility. Only Availability of Medicines i.e. availability of medicines (.054) doesn't have much impact on selection criteria.

\begin{tabular}{|c|l|c|c|}
\hline \multicolumn{4}{|c|}{ Model Summary -Pvth } \\
\hline Step & $\mathbf{- 2}$ log likelihood & Cox \& Snell R Square & Negelkerke R Square \\
\hline 1 & 9617.223 & .153 & .234 \\
\hline $\begin{array}{l}\text { a. Estimation terminated at iteration number 6 because parameter estimates changed } \\
\text { by less than .001 }\end{array}$
\end{tabular}

The following model summary of Pvth explained range of variation in the dependent variablefrom $15.3 \%$ (.153) to $23.4 \%(.234)$. From model summary it is concluded that all the variables under study are having a positive impact on the selection of the private health care facility.

\section{Recommendations For Policy Makers}

From our analysis discussed above we concluded that People are visiting private healthcare facilities because they are receiving good cost of care, Specialised doctors and paramedics/Health Personnel are aimed to provide good \& quality treatment to patients, there is an availability of medicines \& pharmacy facility within health care facility and above all private healthcare facilities have easy accessibility. All these efforts of private healthcare facilities led the private healthcare facilities to continuously strive for and enabling them to bring process, system\& quality improvements in their healthcare facilities. 
While the results for Public healthcare facilities shows poor quality of public healthcare services to patient in terms of cleanliness \&hygiene, non- availability of medicines, absence of specialized doctors, lack of female doctors and other paramedical staff and the inequitable distribution of public healthcare facilities in the city, which in return is making public healthcare services inefficient and unable to provide quality services to people. Karachi's healthcare crises persist despite a lot of genuine efforts by private healthcare facilities to provide good quality healthcare services. In the light of above analysis following recommendations to policy makers can be proposed.

1. Government \& Health Ministry should immediately plan well equipped and state of the art public healthcare facilities (hospitals) in Karachi as the three major tertiary care hospitals Jinnah Postgraduate Medical Center (JPMC), Civil Hospital Karachi (CHK) and Abbasi Shaheed Hospital (ASH ) were established years ago and at that time population was not that much high as it is now.

2. Furthermore, Karachi having six districts and 18 towns, have the right to claim the demand of establishing one general tertiary care hospitals in each of its town so that people can have an easy access to the hospitals in case of emergency or low for price treatment. As study conducted by (Khan, S.R. and S. Kazmi. 1998) also cited access / distance as one of the major reason for not visiting public healthcare facility. Therefore, If the funding are not sufficient to meet the expenses of one hospital in each town, government should work on establishing at least one hospital for two towns.

3. Though Government has taken few steps to equalize the gender imbalances in the health sector. But still there is a dire need to bring gender equality in supply side of hospital service supply chain, especially there is a need to appointment more female doctors, nurses and paramedics staff in public sector hospitals of suburbs of Karachi.

1. 4. Health department must revisit, review and reprioritize the allocation of existing resources in order to make public healthcare facilities more responsive and efficient towards patient's needs. It is important while reprioritization of resources focus should be on both achieving short term \&long term health outcomes and at the same time is able to achieve the long term outcome of population's health status.

4. Innovation in Healthcare is the need of an hour, The areas like Orangi, New Karachi, Gadap and Bin Qasim, lyari where doctors are not available or are reluctant to go because of accessibility concerns ,Government should work to setup E-Health clinics so that their residents can easily connect with doctors for general routine checkups.

5. As our results shows that cost is the only significant factor that is making people visit public healthcare facilities, other than costly treatment at private healthcare facilities, there is an immediate need to address and work on making public healthcare facilities more cost effective for low income patient's needs \& healthcare by providing them free of cost treatment like other megacities of the world (UK, US etc.).

6. Training programs should be launched by the government for the trainings of para medical staff, nurses, doctors etc. So that they will be able to deal with patients in a more efficient manner as Patient-centered care is critical for care quality (Anhang Price R, N. Elliott M, M. Zaslavsky A et al., 2014). 
7. Furthermore, to manage patient flow in ED efficiently and achieve patient satisfaction, public sector hospitals needs to work on different dimensions of Service Supply Chain Management both from demand and supply perspective as previous researches have highlighted that there is a significant impact of supply chain management dimensions on the quality of health care services (Raeeda, et al. 2013).

\section{Conclusions}

This research paper presents the research finding of a cross sectional survey capturing the perceptions \& opinions of the citizens of Karachi regarding public and private healthcare facilities. This paper also attempts to study the gender wise ratio of patients in a public hospital of Karachi to identify the supply side facilities required in hospital to provide efficient patient care to female patients. A total of $\mathrm{N}=11127$ representative sample was taken to gauge perceptions of residents of Karachi about healthcare facilities, their health care facility selection criteria \& concerns of respondents while selecting healthcare facility. The results of a survey provide a precise replication of citizen's opinion about both public $\&$ private healthcare facilities. From our survey results and discussion, the empirical findings and survey results: it is evident that private healthcare facilities are providing better healthcare services and contributing a major role in lowering the burden of public sector healthcare facilities. This further endorses our research rationale that in Karachi, more and more people are visiting private healthcare facilities and that the public sector healthcare facilities are inefficient in performing their due role in providing better and efficient services to people. Moreover patient's realization \& concerns for quality further drives a greater portion of residents towards getting treatment in private healthcare facilities. Hence it can said that private sector healthcare facilities are making far more better efforts as compare to private sector healthcare facilities. Thus in the light of above analysis following recommendations can be given for strengthen public sector hospitals.

\section{References}

Ahmed, S., Khan, A.A. \& Khan, A. (2011). Prioritized Targeting or Mile Wide, Inch Thin: Time to Strategize Public Sector Health Investments, PJPH Volume.1 Issue. 1 December, 2011 pg59-60.

Anhang, Price R, N. Elliott M, M. \& Zaslavsky A et al. (2014). Examining the Role of Patient Experience Surveys in Measuring Health Care Quality. Med Care Res Rev., vol.71:5, pp.522-554.

Asian Development Bank (ADB) (2000). Women in Pakistan, Country Briefing Paper, pp.1-67. 
Chisolm, D.J., Purnell, T.S., Cohen, D.M. \& McAlearney, A.S. (2010). Clinician Perceptions of an Electronic Medical Record During the First Year of Implementation in Emergency Services, Pediatric Emergency Care, vol.26:2, pp.107-110.

Detmer, D.E. (2003). Building the National Health Information Infrastructure for Personal Health, Health Care Services, Public Health and Research, BMC Medical Informatics and Decision Making, (3)1: 57-66

George, Bugliarello (1999). Megacities and the Developing World, The Bridge, Volume 29, Number 4 - Winter 1999

Khan, Amina (2014). The Rise of Karachi as Megacity, Issues and Challenges, Briefing Paper, Policy Development Centre. www.mhhdc.org.

Karkee, R. \& Kadariya, K. (2013). Choice of Healthcare Facility after Introduction of Free Essential Health Services in Nepal, WHO South-East Asia Journal of Public Health, pp.96-100.

Khan, S.R. \& S. Kazmi (1998). Structural Adjustment in Health and Pakistan. Working Paper Series \# 26, pg 1-12.

Jannati, A., Bahrami, MA., Gholizadeh, M., Alizadeh, L. \& Khodayari, MT. (2013). A Survey of Factors Affecting Patients' Decision in Selecting Governmental and Private Hospitals In Tabriz, Iran. J Tourism Res Hospitality 2:1. doi: $10.4172 / 2324-8807.1000110$

New Cities Foundation (2013), An Urban E-Health Project in Rio, [online] Available: http://www.newcitiesfoundation.org/wp-content/uploads/PDF/Research/NewCities-Foundation-E-HealthFull-Report.pdf

Nasir, F., Herani, G.M. \& Nazwaz, A. (2012). Identifying Factors Affecting Patients' Satisfaction Against Quality of Health Care Services: An Investigation from Aga Khan Hospital Karachi, KASBIT Business Journal, vol.5, pp.62-68.

Pappas , G. (2011). Megacities and Health ,PJPH Volume.1 Issue1 December 2011 pg 45. Pakistan -Health system strengthening, World health Organization. http://www.emro.who.int/pak/programmes/health-system-strengthening-hss.html

PPI, (2015, February12). Only 3 Hospitals Entertain Emergency Cases in City of 23.7 Million, Pakistan Today pg, retrieved from: https://www.pakistantoday.com.pk/ 2015/02/12/only-3-hospitals-entertain-emergency-cases-in-city-of-23-7-million/

Rabbani, F. (2011). Improving Quality of Care in Hospitals: Is there a Role for Performance Management? PJPH Volume.1 Issue. 1 December 2011, pg 53-55. 
Raeeda Jamal Al-Saa'da ,Yara Khalid Abu Taleb, Mais Elian Al Abdallat, RasmiAbd Alraheem Al-Mahasneh, Nabil AwniNimer\& Ghazi A. Al-Weshah (2013) Supply Chain Management and Its Effect on Health Care Service Quality: Quantitative Evidence from Jordanian Private Hospitals, Journal of Management and Strategy, Vol. 4, No. 2; 2013pg 42-51

Ali, S. Mubashir (2000). Gender and Healthcare Utilization in Pakistan, The Pakistan Development Review39 : 3 (Autumn 2000) pp. 213-234

Shaikh, B.T. (2011). Do we need to be sceptical about Millennium Development Goals? PJPH Volume. 1 Issue. 1 (December 2011) pg 56-58

Bugliarello, G. (2008). Mega Cities and the Developing World, The Bridge, pg 19-27, retrieved from: https://www.nae.edu/7529/MegacitiesandtheDevelopingWorld

WHO (2004). Equitable Access to Essential Medicines: A Framework for Collective Action. Geneva, pg 1-6, retrieved from: https://apps.who.int/medicinedocs/pdf/ s4962e/s4962e.pdf

Zaidi, Akbar S. (1986). Issues of Pakistan's Health Sector, The Pakistan Development Review, Winter 1986, Vol. 25, No.4 Part pp. 671-682.

\section{Figure}

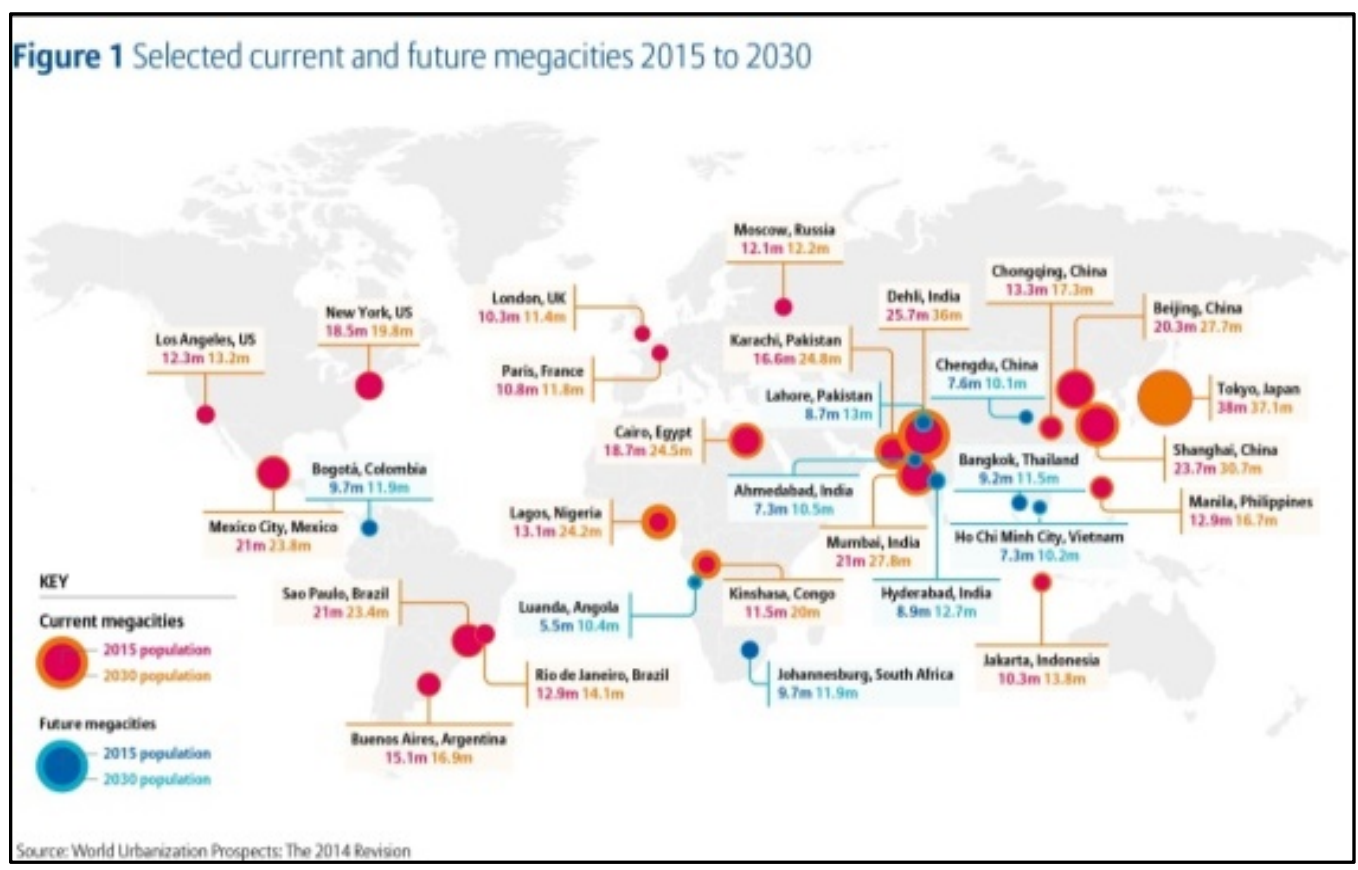

Source: World Urbanization prospects 2014 (revision of 2013) 
196 Strategizing Public Sector Hospitals in Megacity Karachi: A Case Study on Gender Based Healthcare Facility Selection Criteria and Concerns (From Demand and Supply Perspective)

\section{Annexure}

\begin{tabular}{|l|l|l|l|l|}
\hline \multicolumn{4}{|c|}{ Model Summary } \\
\hline Model & R & R Square & Adjusted R square & Std Error of the estimates \\
\hline 1 & $.143^{\mathrm{a}}$ & .020 & .017 & .50113 \\
\hline $\begin{array}{l}\text { a. Predictors: } \\
\text { District of Residence, Level of Education recorded }\end{array}$ \\
\hline
\end{tabular}

\begin{tabular}{|l|l|c|}
\hline \multicolumn{2}{|c|}{ Coefficients $^{\mathbf{a}}$} \\
\hline Model & \multicolumn{1}{|c|}{ Sig. } \\
\hline $\mathbf{1}$ & Constant & .000 \\
\hline & HH3-Age of the household member & .274 \\
\hline & Level of education Recoded & .000 \\
\hline & District of Residence & .023 \\
\hline & income3 & .351 \\
\hline \multicolumn{2}{|l|}{} \\
\hline & Urdu & .100 \\
\hline
\end{tabular}

This is an Extended Research of Research Idea Presented at AICSSH 2017, ST. ANNS College, Oxford University.

Shamaila Burney is Ph.D Research Scholar \& Visiting Faculty in the Department of Public Administration, University of Karachi.

Dr. Khalid Mahmood Iraqi is Professor in the Department of Public Administration and Former Dean, Faculty of Management Sciences, University of Karachi. 